\title{
Quantitative phase microscopy enables precise and efficient determination of biomolecular condensate composition
}

\author{
Patrick M. McCall 1,2,3, Kyoohyun Kim ${ }^{4,5}$, Anatol W. Fritsch ${ }^{1}$, J.M. Iglesias-Artola ${ }^{1}$, \\ L.M. Jawerth ${ }^{1,2}$, Jie Wang ${ }^{1}$, M. Ruer ${ }^{1}$, J. Peychl ${ }^{1}$, Andrey Poznyakovskiy ${ }^{1}$,

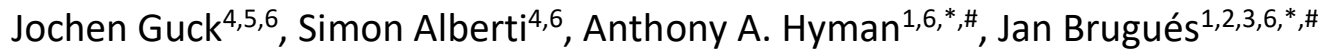

\footnotetext{
${ }^{1}$ Max Planck Institute of Molecular Cell Biology and Genetics, Pfotenhauerstraße 108, 01307 Dresden, Germany

${ }^{2}$ Max Planck Institute for the Physics of Complex Systems, Nöthnitzerstraße 38, 01187 Dresden, Germany

${ }^{3}$ Center for Systems Biology Dresden, Pfotenhauerstraße 108, 01307 Dresden, Germany

${ }^{4}$ Biotechnology Center, Technische Universität Dresden, Tatzberg 47/49, 01307 Dresden, Germany

${ }^{5}$ Max Planck Institute for the Science of Light, Staudstraße 2, 91058 Erlangen, Germany

${ }^{6}$ Cluster of Excellence Physics of Life, Technische Universität Dresden, 01062 Dresden, Germany

* These authors contributed equally

\# Address correspondence to: hyman@mpi-cbg.de; brugues@mpi-cbg.de
}

\section{ABSTRACT}

Many compartments in eukaryotic cells are protein-rich biomolecular condensates demixed from the cyto- or nucleoplasm. Although much has been learned in recent years about the integral roles condensates play in many cellular processes as well as the biophysical properties of reconstituted condensates, an understanding of their most basic feature, their composition, remains elusive. Here we combined quantitative phase microscopy (QPM) and the physics of sessile droplets to develop a precise method to measure the shape and composition of individual model condensates. This technique does not rely on fluorescent dyes or tags, which we show can significantly alter protein phase behavior, and requires 1000fold less material than traditional label-free technologies. We further show that this QPM method measures the protein concentration in condensates to a 3-fold higher precision than the next best label-free approach, and that commonly employed strategies based on fluorescence intensity dramatically underestimate these concentrations by as much as 50fold. Interestingly, we find that condensed-phase protein concentrations can span a broad range, with PGL3, TAF15(RBD) and FUS condensates falling between 80 and $500 \mathrm{mg} / \mathrm{ml}$ under typical in vitro conditions. This points to a natural diversity in condensate composition specified by protein sequence. We were also able to measure temperature-dependent phase equilibria with QPM, an essential step towards relating phase behavior to the underlying physics and chemistry. Finally, time-resolved QPM reveals that PGL3 condensates undergo a contraction-like process during aging which leads to doubling of the internal protein concentration coupled to condensate shrinkage. We anticipate that this new approach will enable understanding the physical properties of biomolecular condensates and their function. 
bioRxiv preprint doi: https://doi.org/10.1101/2020.10.25.352823; this version posted October 25, 2020. The copyright holder for this preprint (which was not certified by peer review) is the author/funder, who has granted bioRxiv a license to display the preprint in perpetuity. It is made available under aCC-BY-ND 4.0 International license.

\section{INTRODUCTION}

Phase separation by demixing is a generic property of polymer solutions, and the properties of the coexisting polymeric phases have long been relevant for energy, material processing and biotechnology applications $(1,2)$. The last decade has seen an explosion in relevance for basic cell biology, as a growing number of compartments in living cells have been appreciated to exist as condensed phases of biopolymers, termed biomolecular condensates, that have demixed from the cyto- or nucleoplasm $(3,4)$. Coexisting demixed phases are distinguished fundamentally by their composition, where phase separation of a simple binary mixture of a polymer in solvent results in a dilute phase coexisting with a polymer-rich condensed phase (Fig. 1A). Knowledge of condensate composition is thus an essential component of a full biophysical characterization of the phase.

Despite this, protein condensate composition has been measured experimentally in only a small number of cases (5-9). Compositions of coexisting phases are traditionally measured spectrophotometrically on the basis of intrinsic UV-absorbance or thermogravimetrically by weighing, evaporating solvent, and reweighing. These are both bulk techniques which, though label-free, require significant volumes of each coexisting phase. While large volumes are not a limitation for many synthetic homopolymers $(10,11)$ or for proteins that can be purified in large quantities from tissue $(5,6)$, they can pose a significant limitation for sequence-specific polymers. In particular, proteins and long or complex polypeptides usually require biological synthesis by overexpression in cell culture. The yield following purification is typically low relative to the amount needed for absorbance, though the needed scale has been achieved in isolated cases $(7,9)$. Composition measurements of micron-sized condensates in situ by microscopy requires 1000 -fold less sample than bulk techniques, and is therefore amenable to complex heteropolymers and proteins. While techniques exist to measure the concentration of protein in individual condensates on the basis of fluorescence intensity $(12,13)$ or fluctuations $(8)$, these approaches rely on the inclusion of fluorescent labels on at least a subset of polymers. Phase behavior is a property determined by the entire molecule, however, including contributions from any protein fusion tag or organic dye present. As we demonstrate below, common labels can measurably alter the composition of condensed protein phases. A label-free microscopic technique is thus essential to accurately characterize condensed biomolecular phases.

To address this need, we present a label-free method to measure the composition of condensed polymer phases based on quantitative phase microscopy (QPM). QPM uses interferometry to precisely measure the optical phase delay accrued as light travels through regions of sample with differing refractive index. By incorporating the physics of sessile droplets, we demonstrate that we are able to extract both the shape and composition of protein condensates from analysis of QPM images. Following validation with silica microspheres and droplets of a Dextran-rich phase, we compare concentration measurements in protein condensates by QPM with three alternative microscopy-based approaches, including optical diffraction tomography, a fluorescence intensity-based method, and a volume-based method, using the proteins PGL3, FUS, and the RNA-binding domain of TAF15 as model condensates. Finally, we demonstrate the suitability of QPM for both temperaturedependent and time-resolved measurements of biomolecular condensate composition. 
bioRxiv preprint doi: https://doi.org/10.1101/2020.10.25.352823; this version posted October 25, 2020. The copyright holder for this preprint (which was not certified by peer review) is the author/funder, who has granted bioRxiv a license to display the preprint in perpetuity. It is made available under aCC-BY-ND 4.0 International license.

QPM Method

McCall et al.

\section{RESULTS}

\section{The refractive index of polymer solutions}

We asked whether the composition of individual micron-sized biomolecular condensates could be inferred by measuring the refractive index difference between the coexisting phases. The refractive index of an aqueous solution of $\mathrm{N}$ components is linear, over some range, in the concentration of each species,

$$
n\left(c_{1}, c_{2}, \cdots, c_{N} \mid \lambda, T\right) \approx n_{0}(\lambda, T)+\sum_{i=1}^{N} \frac{d n}{d c_{i}}(\lambda, T) c_{i},
$$

where $n_{0}$ is the refractive index of the solvent, $d n / d c_{i}$ is the refractive index increment for the $i$ th component, and $\mathrm{i}$ indexes only non-solvent species $(14,15)$. Both $n_{0}$ and $\mathrm{dn} / \mathrm{dc}_{\mathrm{i}}$ are functions of wavelength, $\lambda$, and temperature, $T$. For non-conjugated polymers like proteins, the linear range is quite large, up to at least $50 \mathrm{wt} \%$ at $\lambda=589 \mathrm{~nm}(16)$. This range fully encompasses the concentrations examined in this work. To confirm the validity of this linear approximation near the 650-nm wavelength used for QPM, we measured the refractive index of aqueous polymer solutions at $\lambda=656.3 \mathrm{~nm}$ as a function of polymer concentration (Fig. 1B). We studied polymers representative of three different polymer classes: the protein Bovine Serum Albumin (BSA, $66 \mathrm{kDa}$ ), the unbranched synthetic polymer polyethylene glycol (PEG, $35 \mathrm{kDa}$ ), and a branched sugar (Dextran, $500 \mathrm{kDa}$ ) (Fig. 1B). In all cases, we confirmed that the refractive index increased linearly with polymer concentrations for the ranges probed, with Adj. $R^{2}=0.9999$ on linear fits and identical $y$-intercept values corresponding to the independently-measured refractive index of water (1.331). These results confirm the validity of the linear expansion in (Eq. 1) for diverse polymer solutions under the conditions used for QPM.

Within the linear range, the refractive index difference between two solutions of differing composition is therefore approximately

$$
\Delta n \equiv n_{\text {cond }}-n_{\text {dil }}=\sum_{i=1}^{N} \frac{d n}{d c_{i}} \Delta c_{i}=\sum_{i=1}^{N} \frac{d n}{d c_{i}} c_{i, d i l}\left(P_{i}-1\right)
$$

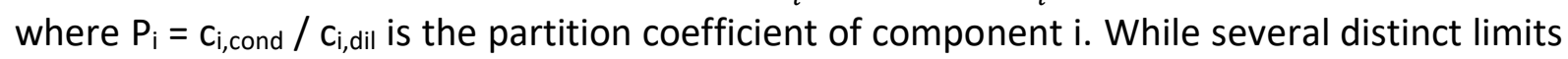
of (Eq. 2) are of practical interest for condensed protein phases, we focus on the simplest in the present work. Specifically, we consider a model in vitro biomolecular condensate in which a single polymer species phase separates with respect to buffer. In the limit of equal partitioning of buffer components between the phases $\left(P_{i}=1\right)$, the only compositional difference between the two phases is the concentration of polymer (and water). As a result, the sum in (Eq. 2) reduces to a single term. In this limit, the difference in polymer concentration between the coexisting phases is directly calculable from the refractive index difference and knowledge of the refractive index increment for the polymer. The refractive index increment for proteins can be estimated directly from amino acid composition (17), and may be readily measured with a refractometer for other polymers when $\sim 100$-uL samples are available over a range of concentrations in excess of typically $1 \mathrm{mg} / \mathrm{ml}$. Knowing the polymer concentration in the dilute phase (for instance by absorbance with a known extinction coefficient) is then sufficient to calculate the polymer concentration in the condensed phase from the concentration difference. We conclude that the absolute polymer concentration in single-component biomolecular condensates can in principle be determined from measurements of the refractive index difference between coexisting phases.

\section{QPM measures the refractive index of micron-sized droplets in situ}

To avoid the need for large volumes of condensed phase, we asked whether we could measure the refractive index difference between micron-sized droplets and their surrounding phase in situ with QPM. As model materials, we examined colloidal silica spheres and sessile 
bioRxiv preprint doi: https://doi.org/10.1101/2020.10.25.352823; this version posted October 25, 2020. The copyright holder for this preprint (which was not certified by peer review) is the author/funder, who has granted bioRxiv a license to display the preprint in perpetuity. It is made available under aCC-BY-ND 4.0 International license.

droplets following gravitational settling onto a passivated glass coverslip attached to a custom temperature control stage ((18), SI Methods). Briefly, QPM is based on measurements of the interference of light passing through these droplet-containing samples and a reference light beam within the microscope that gives rise to holograms (Fig. 1C). From these holograms, we extract computationally the electric field amplitude and the optical phase shift at each image pixel (19). Physically, QPM measures the optical phase shift that develops along a wavefront as it traverses spatial inhomogeneities in refractive index within a sample, such as highrefractive index droplets immersed in a lower-index medium (Fig. 1D).

Within the first Born approximation (20), the optical phase shift $\Delta \varphi$ measured by QPM is proportional to the product of refractive index difference, $\Delta n$, and droplet shape

$$
\Delta \varphi(x, y)=\frac{2 \pi}{\lambda} \Delta n H(x, y)
$$

where $\lambda$ is the imaging wavelength and $H(x, y)$ is the projected height of the droplet along the imaging axis as a function of position in the imaging plane. To unambiguously determine the refractive index difference from (Eq. 3) and a phase image (Fig. 1C), it is thus necessary to know the droplet shape (Fig. 1E). The shape of a sessile droplet in contact with a flat substrate is well described by a spherical cap (21), for which the projected height is given by

$$
H(x, y)=\left\{\begin{array}{llr}
z_{e q}+\sqrt{R^{2}-r^{2}} & \text { for } & r^{2} \leq R_{b}^{2} \\
2 \sqrt{R^{2}-r^{2}} & \text { for } & R_{b}^{2} \leq r^{2} \leq R^{2} \\
0 & \text { for } & R^{2} \leq r^{2}
\end{array}\right.
$$

where $z_{e q}$ is the height of the droplet equatorial plane above the substrate, $\mathrm{R}$ is the radius of the droplet, $R_{b}^{2} \equiv R^{2}-z_{e q}^{2}$ is the squared radius of the circular contact area between droplet and substrate, and $r^{2} \equiv\left(x-x_{c}\right)^{2}+\left(y-y_{c}\right)^{2}$ is the squared radial distance of the point $(x, y)$ from the droplet center $\left(x_{c}, y_{c}\right)$ in a plane parallel to the substrate (Fig. 1E). For the special case of a sphere, $z_{e q}=R$ and the contact area approaches 0 such that (Eq. 4) reduces to $H(x, y)=2 \sqrt{R^{2}-r^{2}}$. The spherical cap approximation is expected to be valid for droplet radii smaller than the capillary length (21). Using interfacial tension measurements typical for biomolecular condensates (22), in conjunction with QPM-based density measurements, we estimate the capillary length to be typically larger than $30 \mu \mathrm{m}$ (SI Fig Capillary Length, SI Text) and restrict the spherical cap approximation to objects smaller than this.

Following image segmentation to identify individual droplets in a QPM phase image, we fit the experimental 2D phase profile of each droplet to a regularized analog of (Eq. 4) and extract estimates of droplet radius, $\mathrm{R}, \Delta n$ and contact angle, $\theta_{c} \equiv \cos ^{-1}\left(z_{e q} / R\right)$, from the fit parameters (SI Text, SI Fig: Code Verification with simulated images). We show the fit along a phase linescan (Fig. 1F) for simplicity of visualization, but the fitting is done on a surface. To accommodate a range of droplet sizes, we acquire an image z-stack in each FOV. The final measurement parameter measurements for each droplet are taken as those from the z-plane with the best fit, typically with Adj. $R^{2}>0.95$ (SI Fig: Data Acquisition and Analysis pipeline, SI Text).

To validate the measured parameter values and the analysis pipeline that produced them, we imaged silica spheres dispersed in glycerol-water-mixtures with a range of refractive indices (Fig. 1G). In each case, the $\Delta n$ values measured by QPM were distributed approximately symmetrically about the population mean and were independent of sphere size (Fig. 1G). This suggests that the deviations are primarily statistical in nature rather than systematic. We next compared the QPM measurements to the theoretical $\Delta n$ (Fig. $1 \mathbf{H}$ ). We calculated the theoretical $\Delta n$ from measurements of each glycerol-water-mixture with a digital refractometer, $n_{\text {silica }}=1.4651$, and accounted for porosity in the colloidal silica 
bioRxiv preprint doi: https://doi.org/10.1101/2020.10.25.352823; this version posted October 25, 2020. The copyright holder for this preprint (which was not certified by peer review) is the author/funder, who has granted bioRxiv a license to display the preprint in perpetuity. It is made available under aCC-BY-ND 4.0 International license.

spheres (23), which we estimate to be $35 \%$. We found that our QPM measurements were in excellent agreement with the theoretical estimates for index differences spanning an order of magnitude (Fig. $1 \mathbf{H}$ ). These results confirm the validity of the $1^{\text {st }}$ order Born approximation for index differences as large as 0.085 and the analysis pipeline for spheres.

To check whether the analysis also applies to sessile droplets with a spherical cap geometry, we employed a PEG/Dextran aqueous two-phase system (ATPS). Upon mixing concentrated solutions of PEG-35k and Dextran-500k, the polymers segregate into a dense Dextran-rich bottom phase and a less-dense PEG-rich top phase (24). Following phase equilibration, we dispersed a small volume of the bottom phase into a larger volume of top phase to generate micron-sized droplets of bottom phase. Following gravitational settling onto coverglass, we used QPM to measure the $\Delta n$ between these sessile Dextran-rich droplets and the surrounding PEG-rich phase (Fig. $1 \mathrm{H}$, red). Because we could readily prepare $>100 \mu \mathrm{L}$ volumes of each phase with the PEG/Dextran ATPS, we were also able to measure the refractive index of each phase directly with a digital refractometer. Again, we found excellent agreement between the $\Delta n$ values measured by QPM and refractometry, now for the spherical-cap geometry of a sessile droplet. Taken together, these results demonstrate that QPM enables accurate measurement of the refractive index difference between micron-sized droplets and surrounding solution.

\section{QPM measures protein concentration in condensates with high precision}

With the methodology validated, we turned our attention to protein condensates. We first looked at condensed phases of the protein PGL3. PGL3 is a major component of condensates known as $P$ granules in C. elegans (25) and forms condensates in vitro under low salt (26). While several biophysical properties of PGL3 condensates have been measured (22, 27), their composition remains unknown. To measure PGL3 concentration, we used QPM on PGL3 condensates formed in vitro $\left(\mathrm{pH} \mathrm{7.4,75} \mathrm{mM} \mathrm{KCl,} 25^{\circ} \mathrm{C}\right)$ following gravitational settling (Fig. 2A). After conversion of the measured $\Delta n$ values to concentration by (Eq. 2), we found the concentration in individual PGL3 condensates to be symmetrically distributed about a mean of $87.0 \pm 0.1 \mathrm{mg} / \mathrm{ml}$ (s.e.m., $\mathrm{N}=269$ ) with a standard deviation of $1.7 \mathrm{mg} / \mathrm{ml}$ (Fig. $2 \mathrm{C}$ ). The coefficient of variation (CV) for the measurement is $1.9 \%$. This small value reflects the high precision of the QPM method as well as the low droplet-to-droplet heterogeneity expected for coexisting condensed phases.

For comparison, we also measured PGL3 concentration using Optical Diffraction Tomography (ODT). Like QPM, ODT is also a label-free holographic microscopy technique that is sensitive to spatial variations in sample refractive index. ODT has been used recently to measure the composition of G3BP1 condensates (28). Using ODT, we measured the concentration of PGL3 in condensates to be $99.2 \pm 5.9 \mathrm{mg} / \mathrm{ml}$ (Fig. 2B,C). Although this value is somewhat higher than our measurement by QPM, we note that the discrepancy may be accounted for by several small differences in wavelength ( $532 \mathrm{vs.} 650 \mathrm{~nm}$ ), temperature $(21.5$ vs. $25.0^{\circ} \mathrm{C}$ ), and ionic strength ( 87 vs. $75 \mathrm{mM} \mathrm{KCl}$ ) between the ODT and QPM measurements, respectively. In light of these differences, we conclude that the techniques offer comparable measurement accuracy. However, we note that the ODT data shows a significantly larger drop-to-drop variation (5.9\% CV) and a slight asymmetry, with a more pronounced tail at lower values (Fig. 2C). The symmetry and low variance in the droplet concentration distribution measured by QPM suggests that the asymmetry and relative heterogeneity measured by ODT is not representative of the underlying sample. Taken together, these data show that while the accuracy of the techniques is likely comparable given differences in experimental conditions, QPM achieves a 3-fold higher precision. 
bioRxiv preprint doi: https://doi.org/10.1101/2020.10.25.352823; this version posted October 25, 2020. The copyright holder for this preprint (which was not certified by peer review) is the author/funder, who has granted bioRxiv a license to display the preprint in perpetuity. It is made available under aCC-BY-ND 4.0 International license.

We next asked how QPM compares to techniques requiring fluorescent tags, which are commonly used to visualize and characterize condensates. In particular, partition coefficients are often estimated on the basis of the relative fluorescence intensities in the two phases $(12,13)$. To assess the validity of this approach, we used condensates formed from the RNA-binding domain of the protein TAF15 fused with a SNAP-tag (SNAP-TAF15(RBD)), whose saturation concentration in vitro has been determined previously (29). We mixed a small fraction of proteins conjugated to the organic dye AlexaFluor546 (AF546-SNAP-TAF15(RBD)) to create a sparsely-labeled $(<10 \%)$ solution and induced phase separation by dilution into low-salt buffer (29). We imaged condensates with point-scanning confocal fluorescence microscopy (Fig. 2D), using a pinhole closed to 0.5 Airy Units to reduce intensitymislocalization effects related to the finite point-spread function of the microscope. Avoiding pixels near condensate interfaces, we measured a partition coefficient of 65 for SNAPTAF15(RBD) condensates (Fig. 2E). Together with a dilute phase concentration of $1.96 \pm 0.09 \mathrm{uM}(0.123 \pm 0.006 \mathrm{mg} / \mathrm{ml})$ measured by absorbance (29), our intensity-based partition coefficient measurement implies a condensed phase concentration of $8.0 \pm 1.7$ $\mathrm{mg} / \mathrm{ml}(130 \pm 30 \mathrm{uM})$. Surprisingly, this is nearly 50 -fold lower than the $393.7 \pm 7.2 \mathrm{mg} / \mathrm{ml}$ we measure for SNAP-TAF15(RBD) by QPM (Fig. 2F). We suspect that this significant discrepancy is likely due primarily to differences in the fluorescence quantum yield of the AlexaFluor dye between the dilute and condensed phases. In particular, the vastly higher protein concentration in the condensed phase could lead to a greater prevalence of fluorescence quenching than is observed in the dilute phase (30).

To confirm that the significantly lower concentration estimated from an intensitybased partition coefficient stems from systematic errors related to calibration of the fluorescence intensity, we also calculated the condensed phase protein concentration by measuring the ratio of condensed and dilute-phase volumes. For binary mixtures, knowledge of both phase volumes along with the total protein concentration, and the concentration in one phase is sufficient to calculate the concentration in the remaining phase by conservation of mass. Importantly, we use fluorescence intensity to segment images in this volume-based method, but the absolute magnitude of the intensity is otherwise not used. We encapsulated a dispersion containing AF546-SNAP-TAF15(RBD) condensates into water-in-oil emulsion drops immediately following induction of phase separation. This procedure helps to minimize protein loss at chamber surfaces and creates several enclosed reaction volumes that can be measured independently via confocal microscopy. Using this volume-based method, we measure a condensed phase concentration of $380 \pm 130 \mathrm{mg} / \mathrm{ml}$ (Fig. 2F). Though significantly less precise, this value is consistent with the measurement by QPM. Taken together, these data indicate that partition coefficients based on fluorescence intensity are prone to dramatically underestimate the true concentrations in biomolecular condensates in vitro.

\section{Protein condensate composition is determined my molecular properties}

Our measurements of protein concentrations in condensates derived from three different proteins span a range from 80 to $400 \mathrm{mg} / \mathrm{ml}$, and are summarized in Table 1 . We draw three general conclusions from these data. First, the presence of fusion tags such as mEGFP alters protein phase behavior. In the case of the PGL3, the tag increases the protein concentration in the condensed phase by a small but measurable $14 \%$. Because the tag increases the molecular weight of the construct by more than $14 \%$, this actually corresponds to in a decrease in the molar protein concentration in the condensate. This is consistent with the tag imparting a modest solubilizing effect. Second, this 5-fold range in concentrations is quite large relative to the precision with which composition can be measured. This indicates 
bioRxiv preprint doi: https://doi.org/10.1101/2020.10.25.352823; this version posted October $25,2020$. The copyright holder for this preprint (which was not certified by peer review) is the author/funder, who has granted bioRxiv a license to display the preprint in perpetuity. It is made available under aCC-BY-ND 4.0 International license.

that there is no single definitive composition representative of protein condensates, but rather that the concentration is dictated by protein amino acid sequence and the characteristics of the solvent and environment. This is consistent with expectations for regular solution theory, and underscores the necessity of measuring composition to inform mechanistic interpretation of other condensate properties like mechanics. Finally, we note that protein represents nearly 30 percent of the condensate volume in SNAP-TAF15(RBD) condensates (Table 1), a value comparable to protein crystals (31). While this is very high relative to typical protein solutions in the lab, we argue that it is not unreasonably high for a condensed protein phase, as condensates of the disordered Ddx4 protein (7), globular eyelens proteins (5), and synthetic polyelectrolyte complex coacervates (11) all have comparable polymer concentrations.

\section{QPM allows to measure temperature-dependent binodals}

We next asked whether we could measure the composition of a condensate as a function of temperature - the condensed branch of the binodal curve (Fig. 1A). This possibility would enable direct comparison to different physical theories, including Flory-Huggins and its extensions $(8,9)$, the random phase approximation $(7,32)$, and $\operatorname{DLVO}(10,11)$. Thus measuring the temperature-dependent binodal may enable identifying the appropriate physical model to describe the thermodynamics of a given condensate. Using a water-cooled stage to control sample temperature, we measured the refractive index difference between GFP-TAF15(RBD) condensates and the coexisting dilute phase at four temperatures (Fig. 3A). We found that the refractive index decreases monotonically with increasing temperature. To properly convert these index differences to concentrations, we sought to account for the temperaturedependence of the other terms in (Eq. 1), specifically that of the solvent and the refractive index increment, $\mathrm{dn} / \mathrm{dc}$. We measured the refractive index of the buffer on a temperaturecontrolled digital refractometer (Fig. 3B), and found that it also decreased with temperature. This is consistent with the reduction in overall electron density in the liquid upon heating owing to the positive thermal expansion coefficient of water. For the refractive index increment, we employed an empirical relationship from the literature (17), which also predicts a temperature-dependent decrease (Fig. $3 C$ ). Accounting for these effects, we could calculate the protein concentration in the condensates at each temperature (Fig. 3D). The decrease in concentration with temperature is indicative that GFP-TAF15(RBD) has an upper critical solution temperature as shown in Fig. 1A. The persistence of condensates at $50{ }^{\circ} \mathrm{C}$ indicates that the critical temperature is at a still higher temperature, which would likely lead to unfolding of the GFP tag. Taken together, these data demonstrate that QPM is fully compatible with temperature-dependent binodal measurements of biomolecular condensates.

\section{QPM reveals a time-dependent increase in PGL3 condensate density}

Motivated by recent work that demonstrated that the mechanical properties of many protein condensates undergo an aging process in which they harden (27), we asked whether the composition of individual condensates changed over time. We hypothesized that there may be a corresponding change in composition as condensates age. To this end, we used QPM to measure the composition of PGL3 condensates over 20 hours (Fig. 4). During this time period, we observed droplets to noticeably shrink (Fig. 4A, top). While the shrinkage would be apparent by simple brightfield imaging, QPM imaging indicated that the optical phase shift also increased with time, despite the reduction in droplet size (Fig. 4A, bottom). By fitting the QPM data as before, we were able to precisely measure the composition (Fig. 4B) and volume 
bioRxiv preprint doi: https://doi.org/10.1101/2020.10.25.352823; this version posted October 25, 2020. The copyright holder for this preprint (which was not certified by peer review) is the author/funder, who has granted bioRxiv a license to display the preprint in perpetuity. It is made available under aCC-BY-ND 4.0 International license.

(Fig. 4C) of individual condensates over this timeframe, revealing surprisingly coordinated dynamics. While the concentration increases steadily over the first 10 hours, there is a sudden acceleration around 12 hours, followed by a reduction in rate toward the end of the recording (Fig. 4B). The evolution of the condensate volume with time is very similar but inverted, with a slow decrease followed by a steep decrease around 12 hours (Fig. 4C). From these concentration and volume data, we calculated the number of proteins in the condensate (Fig. 4D). For the condensate depicted in Fig. 4A, we found that the nearly 2 -fold concentration increased was approximately balanced by a volume decrease of just over 2fold, such that the total number of protein molecules in the condensate decreased by only 15 $\%$. To accommodate the observed volume reduction and protein retention, we infer that the condensate necessarily expelled a significant amount of solvent.

To quantify whether this near cancellation in... was particular of our PGL3, we analyzed the dynamics of 24 additional condensates with a range of initial sizes over the same period (Fig. 4E-F). Strikingly, we found that the kinetics and extent of concentration increase were identical for all condensates, independent of size (Fig. 4E). The kinetics and extent of the volume decrease, however, both showed systematic size dependencies, with smaller condensates losing volume faster and to greater extent than larger condensates (Fig. 4F). As a result, the fraction of molecules retained shows a marked size-dependence, with condensates that are larger initially retaining more molecules (Fig. 4G). We speculate that the size dependence in the volume kinetics may stem from Ostwald ripening operating in parallel with an additional as yet unknown process driving the contraction and water expulsion. In particular, the preferential flux of protein from small condensates to larger ones under an Ostwald ripening scenario is qualitatively consistent with the slower initial rate of shrinkage and lower total volume loss we observe in larger condensates (Fig. 4F). While we will investigate this hypothesis and the identification of the process driving the contraction to future work, these data demonstrate that a dynamic process drives a 2-fold increase in PGL3 concentration within condensates on the 24-hr timescale.

\section{DISCUSSION}

Here we demonstrated that QPM enables precise label-free measurements of individual um-sized condensates in an open system and small volumes amenable to external temperature modulation. This approach overcomes the limitations of existing methods, requiring 1000-fold less condensed-phase material relative to bulk absorbance or TGA measurements and not requiring the exogenous fluorescent tag that is obligatory for measurements based on fluorescence intensity or fluctuations. The use of Tags introduce two distinct issues worth discussing.

First, tag properties (like quantum yield) can be different in the two phases, making calibration of intensities difficult and leading to inaccurate measurements. While most pronounced for solvent exposed fluorophores like AlexaFluor, we also measured a marked difference for GFP (SI Fig: Fluorescence partition coefficients), which is often regarded as relatively insensitive to solvent. Our data show that partition coefficient measurements based on fluorescence intensities with common fluorophores can underestimate true values by up to 50-fold owing to differences in fluorescence between phases, even when only a small fraction of proteins are labeled. This suggests that the use of fluorescence intensity is an unreliable method to determine partition coefficients in biomolecular condensates in vitro, where the chemical environment in the dilute and condensed phases can differ greatly. We note that an increased prevalence in the condensed phase of processes that reduce the fluorescence quantum yield, such as collisional quenching and intersystem crossing, or that 
bioRxiv preprint doi: https://doi.org/10.1101/2020.10.25.352823; this version posted October $25,2020$. The copyright holder for this preprint (which was not certified by peer review) is the author/funder, who has granted bioRxiv a license to display the preprint in perpetuity. It is made available under aCC-BY-ND 4.0 International license.

reduce the fraction of excitable fluorophores, such as static quenching, could all contribute to the reduced fluorescence efficiency we observe in condensates (30). Of these, intersystem crossing and static quenching introduce transitions into relatively long-lived dark states, giving rise to fluorophore "blinking." Importantly, fluorophore blinking on timescales longer than the FCS sampling rate introduces an additional fluctuation mechanism that reduces the average number of detected molecules in the measurement volume (SI Fig: FCS with blinking). Therefore, differences in the photophysical context of the fluorophore between the dilute and condensed phases can in principle introduce systematic errors to FCS-based measurements of concentration as well, though these errors are likely much smaller in magnitude those we observed for intensity-based measurements.

Second, tags can alter polymer-polymer and polymer-solvent interactions, and thereby altering the phase behavior of labeled polymers relative to unlabeled ones, including both $c_{D i l}$ and ccond. This leads to measurements of a material different than the material of interest. Exogenous interactions contributed by GFP-derived fluorophores as well as planar aromatic dyes are known to impact partitioning in condensates (33), confounding interpretation of concentration measurements based on fluorescence intensity or fluctuations. In vitro, we found that the presence of an mEGFP-tag on PGL3 altered the condensed phase concentration and that the saturation concentration of SNAP-TAF15(RBD) was reduced more than 2-fold when an AlexaFluor546 dye is conjugated to the SNAP-tag relative to when the dye is absent (SI Fig: Effects of tags). These observations highlight the necessity for label-free methods to measure condensate composition.

In this work, we also compared the label-free QPM-based method against other labelfree in situ techniques, including ODT and an approach based on volume measurements. ODT gave good agreement with QPM with the advantage of obtaining the condensate shape explicitly without assumptions about wetting. This makes it particularly well-suited for in vivo applications where droplet shape is likely more difficult to predict from first principles. However, high drop-to-drop variability, potentially due to laser speckle noise, leads to 3-fold lower precision compared to QPM. Additionally, the immersion medium required by the highNA objectives used for ODT introduces thermal coupling between the sample and the objectives, which is incompatible with rapid and uniform temperature changes. The second method we used was based on volume measurements. These are in turn based on conservation of mass, and thus enable an explicit determination of concentration only in binary or quasi-binary systems, requiring a considerable equilibration time to ensure that all condensed phase volume is counted. The volume measurements can be performed with dry objectives, making them amenable to dynamic temperature measurements. Both these approaches offer reasonable accuracy though with reduced precision compared to QPM. We conclude that the QPM-based method presented here provides accurate label-free measurements of condensate composition on individual droplets with smaller volume requirement and better precision than any other comparable technique.

For all of the constructs and conditions of quasi-binary systems (single protein in buffer) considered here, we measured the protein concentration to be in the range of 80-500 $\mathrm{mg} / \mathrm{ml}$. To the best of our knowledge, this is also true of all but one of the previous measurements of polymer content in condensates of quasi-binary systems, including condensates of intrinsically disordered proteins $(7,9)$, globular proteins $(5,6)$, and even polyelectrolyte complex coacervates which contain two polymers $(10,11)$. The single outlier is for LAF1, in which a protein concentration of $6 \mathrm{mg} / \mathrm{ml}$ was measured in LAF1 condensates by ultrafast scanning FCS (8). In light of the comparably low protein concentration reported recently in condensates containing G3BP1 and long RNA (28), it is conceivable that the 
bioRxiv preprint doi: https://doi.org/10.1101/2020.10.25.352823; this version posted October $25,2020$. The copyright holder for this preprint (which was not certified by peer review) is the author/funder, who has granted bioRxiv a license to display the preprint in perpetuity. It is made available under aCC-BY-ND 4.0 International license.

inadvertent presence of RNA could account for the low LAF1 concentration measured by FCS. Although the precise concentration in a given condensate is dependent upon environmental factors such as temperature, ionic strength and $\mathrm{pH}$, the common range of existing measurements suggests that $80-500 \mathrm{mg} / \mathrm{ml}$ may be typical of condensed protein phases in quasi-binary systems in vitro. A systematic investigation of the physical limits for the range of condensate densities accessible to individual proteins is an interesting avenue for future work.

It is well recognized that the physical properties of biomolecular condensates play fundamental roles in regulating diverse biological processes (4). This condensate role has driven substantial interest in tracing the emergence of condensate thermodynamics and mechanics to the properties of the constituent molecules. In particular, there has been a surge in theoretical and simulation extending classic polymer physics principles from homopolymers on protein polymers in which sequence heterogeneity plays a central role $(9,32,34-38)$. Rigorous testing of predictions from different physical theories requires measurements of both binodal branches and, owing in large part to the excessive sample requirements of traditional label-free methods, has been achieved very infrequently for native protein sequences $(7,9)$. In addition, condensate mechanics are frequently measured semiquantitatively, but usually not interpreted in terms of well-established theories for the dynamics of polymer solutions. We suspect this is because the polymer concentration is an essential parameter for determining even which regime of a given theory should be considered, making modeling in its absence challenging.

We anticipate that the ability of the QPM method presented here to reveal the composition of a condensed biomolecular phase efficiently and precisely without recourse to labeling will enable rapid progress in testing predictions of condensate thermodynamics and mechanics from physical theory, simulations, and even machine learning. The refinement of these physical models is critically important because the ability to accurately predict condensate properties is what currently limits our ability to design them from the bottom up. Such an understanding could enable rational engineering of protein mutations to selectively tune condensate properties, opening the door to directly query the impact of a specific property on down-stream biological function. The precise QPM-based method we present here thus fills an essential gap, enabling a bottom-up physical approach to systematically probe the relationship between the composition, physical properties, and functionality of condensed biomolecular phases.

\section{MATERIALS AND METHODS}

Protein constructs used in this work were purified and stored as described previously $(26,29)$. To induce phase separation, we mixed protein in high-salt storage buffer $(300 \mathrm{mM}$ $\mathrm{KCl}$ for PGL3 constructs, $500 \mathrm{mM} \mathrm{KCl}$ for TAF15 and FUS constructs) with storage buffer lacking monovalent salt, "Dilution Buffer", to reach the desired final salt concentration. An aliquot of Dilution Buffer was supplemented to $1 \mathrm{mM}$ with fresh DTT prior to each day's experiments. For control measurements, 10-um silica microspheres were purchased from Whitehouse Scientific (Waverton, UK), and glycerol-water-mixtures were prepared by weight to the desired refractive index. Bead-containing dispersions were prepared by gently dipping a 10$\mathrm{uL}$ pipette tip into a stock of dry beads, transferring the pipette tip to a $40 \mathrm{uL}$ volume of glycerol-water mixture, and pipette mixing to disperse. The PEG/Dextran ATPS was prepared as described previously (24).

Quantitative phase microscopy (QPM) measurements were performed using a coherence-controlled holographic microscope (Q-Phase, Telight (formerly TESCAN), Brno, CZ) with a tungsten-halogen bulb lightsource filtered by a $10-\mathrm{nm}$ bandwidth notch filter centered 
bioRxiv preprint doi: https://doi.org/10.1101/2020.10.25.352823; this version posted October 25, 2020. The copyright holder for this preprint (which was not certified by peer review) is the author/funder, who has granted bioRxiv a license to display the preprint in perpetuity. It is made available under aCC-BY-ND 4.0 International license.

at $650 \mathrm{~nm}$. All measurements were performed with 40x dry objectives (NA $=0.90$ ) except those for SNAP-TAF15(RBD) reported in Fig. 2F, for which the 20x dry objectives were used. In all cases, the condenser aperture was set to an NA of 0.30 . Immediately following phase separation, $\sim 5 \mu \mathrm{L}$ of sample was loaded into a temperature-controlled flowcell, sealed with two-component silicone glue Twinsil (Picodent, Wipperfürth, DE), and allowed to settle under gravity for $\sim 10$ minutes prior to data collection. Flowcells were constructed with a $30 \times 24 \times 0.17$ $\mathrm{mm}^{3}$ PEGylated coverslip and a $75 \times 25 \times 1 \mathrm{~mm}^{3}$ sapphire slide as bottom and top surfaces, respectively, using parafilm strips as spacers. Proportional-integral-derivative (PID)-controlled Peltier elements affixed to the sapphire slide enabled regulation of flowcell temperature, as previously described (18). The sapphire, coverslip, and spacers were adhered by heating the assembled flowcell to $50^{\circ} \mathrm{C}$ for $5 \mathrm{~min}$, then returning to the desired temperature for the first measurement, typically to $21^{\circ} \mathrm{C}$ or $25^{\circ} \mathrm{C}$.

For each sample, hologram z-stacks ( $d z=0.2 \mu \mathrm{m}$, first plane typically near the coverglass surface) were acquired for several fields of view. Q-PHASE software was used to construct amplitude and compensated phase images from the raw holograms. Pixels in the phase images are $0.157 \mu \mathrm{m}$ per side for the $40 \mathrm{x}$, and pixel intensities are in units of radians. All phase images were analyzed in MATLAB using custom code.

Optical Diffraction Tomography (ODT) measurements were performed using a custombuilt microscope employing a 532-nm laser, as described previously (39). Tomogram reconstruction and image analysis was performed as described previously $(40,28)$.

\section{ACKNOWLEDGEMENTS}

We thank T. Franzmann, T. Harmon, E. Filippidi, and other members of the Brugues, Hyman, Alberti, Julicher, and Weber groups for frequent and fruitful discussions. We thank T. Slabý and M. Šicner of Telight for support with the QPHASE microscope and E. Bittrich and R. Schulze of the Leibniz Institute for Polymer Research for assistance with multi-wavelength refractometry measurements. We also thank the MPI-CBG Core Facilities, particularly the Light Microscopy Facility and the Protein Expression and Purification Core, for their support. PMM was supported by an ELBE Postdoctoral Fellowship from the CSBD.

\section{AUTHOR CONTRIBUTIONS}

PMM, JP, AAH, and JB conceived the project. PMM and JMW performed QPM measurements. PMM and KK performed ODT measurements. PMM performed intensity-based fluorescence microscopy measurements. PMM, AWF and JMI-A performed the volume-based measurements. PMM, KK, AWF, JMI-A, contributed analytic tools. JW, MR, and AP contributed new reagents. $P M M$ analyzed $Q P M$ and intensity-based measurement data. KK analyzed ODT data. AWF and JMI-A analyzed volume-based measurement data. SA, JG, AAH, and JB supervised the work. PMM wrote the paper and incorporated input from AAH and JB.

\section{REFERENCES}

1. M. Rubinstein, R. H. Colby, Polymer Physics, 1st Ed. (Oxford University Press, 2003).

2. C. E. Sing, S. L. Perry, Recent progress in the science of complex coacervation. Soft Matter 16, 2885-2914 (2020).

3. A. A. Hyman, C. A. Weber, F. Julicher, Liquid-Liquid Phase Separation in Biology. Annu. Rev. Cell Dev. Biol. 30, 39-58 (2014). 
bioRxiv preprint doi: https://doi.org/10.1101/2020.10.25.352823; this version posted October 25,2020 . The copyright holder for this preprint (which was not certified by peer review) is the author/funder, who has granted bioRxiv a license to display the preprint in perpetuity. It is made available under aCC-BY-ND 4.0 International license.

\section{QPM Method}

McCall et al.

4. S. F. Banani, H. O. Lee, A. A. Hyman, M. K. Rosen, Biomolecular condensates: organizers of cellular biochemistry. Nat. Rev. Mol. Cell Biol. 18, 285-298 (2017).

5. V. G. Taratuta, Andreas. Holschbach, G. M. Thurston, Daniel. Blankschtein, G. B. Benedek, Liquid-liquid phase separation of aqueous lysozyme solutions: effects of $\mathrm{pH}$ and salt identity. J. Phys. Chem. 94, 21402144 (1990).

6. M. L. Broide, C. R. Berland, J. Pande, O. O. Ogun, G. B. Benedek, Binary-liquid phase separation of lens protein solutions. Proc. Natl. Acad. Sci. 88, 5660-5664 (1991).

7. J. P. Brady, et al., Structural and hydrodynamic properties of an intrinsically disordered region of a germ cell-specific protein on phase separation. Proc. Natl. Acad. Sci. 114, E8194-E8203 (2017).

8. M.-T. Wei, et al., Phase behaviour of disordered proteins underlying low density and high permeability of liquid organelles. Nat. Chem. advance online publication (2017).

9. E. W. Martin, et al., Valence and patterning of aromatic residues determine the phase behavior of prionlike domains. Science 367, 694-699 (2020).

10. E. Spruijt, A. H. Westphal, J. W. Borst, M. A. Cohen Stuart, J. van der Gucht, Binodal Compositions of Polyelectrolyte Complexes. Macromolecules 43, 6476-6484 (2010).

11. L. Li, et al., Phase Behavior and Salt Partitioning in Polyelectrolyte Complex Coacervates. Macromolecules (2018) https:/doi.org/10.1021/acs.macromol.8b00238 (April 23, 2018).

12. S. F. Banani, et al., Compositional Control of Phase-Separated Cellular Bodies. Cell 166, 651-663 (2016).

13. P. M. McCall, et al., Partitioning and Enhanced Self-Assembly of Actin in Polypeptide Coacervates. Biophys. J. 114, 1636-1645 (2018).

14. W. Heller, Remarks on Refractive Index Mixture Rules. J. Phys. Chem. 69, 1123-1129 (1965).

15. G. Popescu, et al., Optical imaging of cell mass and growth dynamics. Am. J. Physiol.-Cell Physiol. 295, C538-C544 (2008).

16. R. Barer, S. Tkaczyk, Refractive Index of Concentrated Protein Solutions. Nature 173, 821-822 (1954).

17. H. Zhao, P. H. Brown, P. Schuck, On the Distribution of Protein Refractive Index Increments. Biophys. J. 100, 2309-2317 (2011).

18. M. Mittasch, et al., Non-invasive perturbations of intracellular flow reveal physical principles of cell organization. Nat. Cell Biol. 20, 344-351 (2018).

19. T. Slabý, et al., Off-axis setup taking full advantage of incoherent illumination in coherence-controlled holographic microscope. Opt. Express 21, 14747-14762 (2013).

20. M. Born, E. Wolf, Principles of Optics, 7th Ed. (Cambridge University Press, 2019).

21. J. Park, J. Park, H. Lim, H.-Y. Kim, Shape of a large drop on a rough hydrophobic surface. Phys. Fluids 25, 022102 (2013).

22. L. M. Jawerth, et al., Salt-Dependent Rheology and Surface Tension of Protein Condensates Using Optical Traps. Phys. Rev. Lett. 121, 258101 (2018).

23. F. C. Cheong, K. Xiao, D. J. Pine, D. G. Grier, Holographic characterization of individual colloidal spheres' porosities. Soft Matter 7, 6816-6819 (2011). 
bioRxiv preprint doi: https://doi.org/10.1101/2020.10.25.352823; this version posted October 25,2020 . The copyright holder for this preprint (which was not certified by peer review) is the author/funder, who has granted bioRxiv a license to display the preprint in perpetuity. It is made available under aCC-BY-ND 4.0 International license.

24. E. Atefi, D. Fyffe, K. B. Kaylan, H. Tavana, Characterization of Aqueous Two-Phase Systems from Volume and Density Measurements. J. Chem. Eng. Data 61, 1531-1539 (2016).

25. C. P. Brangwynne, et al., Germline P Granules Are Liquid Droplets That Localize by Controlled Dissolution/Condensation. Science 324, 1729-1732 (2009).

26. S. Saha, et al., Polar Positioning of Phase-Separated Liquid Compartments in Cells Regulated by an mRNA Competition Mechanism. Cell 166, 1572-1584.e16 (2016).

27. L. M. Jawerth, et al., Protein condensates as aging Maxwell fluids. Science (accepted).

28. J. Guillén-Boixet, et al., RNA-Induced Conformational Switching and Clustering of G3BP Drive Stress Granule Assembly by Condensation. Cell 181, 346-361.e17 (2020).

29. J. Wang, et al., A Molecular Grammar Governing the Driving Forces for Phase Separation of Prion-like RNA Binding Proteins. Cell 174, 688-699.e16 (2018).

30. J. R. Lakowicz, "Quenching of Fluorescence" in Principles of Fluorescence Spectroscopy, (Springer, Boston, MA, 2006), pp. 277-330.

31. B. W. Matthews, Solvent content of protein crystals. J. Mol. Biol. 33, 491-497 (1968).

32. Y.-H. Lin, J. D. Forman-Kay, H. S. Chan, Theories for Sequence-Dependent Phase Behaviors of Biomolecular Condensates. Biochemistry (2018) https:/doi.org/10.1021/acs.biochem.8b00058 (March 16, 2018).

33. C. W. Pak, et al., Sequence Determinants of Intracellular Phase Separation by Complex Coacervation of a Disordered Protein. Mol. Cell 63, 72-85 (2016).

34. G. L. Dignon, W. Zheng, Y. C. Kim, R. B. Best, J. Mittal, Sequence determinants of protein phase behavior from a coarse-grained model. PLOS Comput. Biol. 14, e1005941 (2018).

35. T. K. Lytle, L.-W. Chang, N. Markiewicz, S. L. Perry, C. E. Sing, Designing Electrostatic Interactions via Polyelectrolyte Monomer Sequence. ACS Cent. Sci. 5, 709-718 (2019).

36. F. G. Quiroz, A. Chilkoti, Sequence heuristics to encode phase behaviour in intrinsically disordered protein polymers. Nat. Mater. 14, 1164-1171 (2015).

37. J. R. Simon, N. J. Carroll, M. Rubinstein, A. Chilkoti, G. P. López, Programming molecular self-assembly of intrinsically disordered proteins containing sequences of low complexity. Nat. Chem. 9, 509-515 (2017).

38. C. E. Sing, Micro- to macro-phase separation transition in sequence-defined coacervates. J. Chem. Phys. 152, 024902 (2020).

39. S. Abuhattum, et al., Intracellular Mass Density Increase Is Accompanying but Not Sufficient for Stiffening and Growth Arrest of Yeast Cells. Front. Phys. 6 (2018).

40. K. Kim, et al., High-resolution three-dimensional imaging of red blood cells parasitized by Plasmodium falciparum and in situ hemozoin crystals using optical diffraction tomography. J. Biomed. Opt. 19, 011005 (2013). 
bioRxiv preprint doi: https://doi.org/10.1101/2020.10.25.352823; this version posted October 25, 2020. The copyright holder for this preprint (which was not certified by peer review) is the author/funder, who has granted bioRxiv a license to display the preprint in perpetuity. It is made available under aCC-BY-ND 4.0 International license.

\section{FIGURE CAPTIONS}

Fig 1: QPM measures the refractive index of micron-size droplets in situ

(A) Schematic of UCST binodal (solid black) and spinodal (dashed black) with example snapshots of samples in the 1- and 2-phase regimes. (B) Refractive index is a linear function of component concentration for three model polymers (BSA, Dextran, and PEG) measured in water at $\lambda=654.6 \mathrm{~nm}$. Solid lines are linear fits to data, in all cases with $A d j . R^{2}=0.9999$ and $y$-intercept identical to water (without constraint). Inset: slopes ( $d n / d c)$ for each polymer with $95 \%$ confidence intervals. (C) Hologram, Amplitude, and Phase (QPM) images of $10-\mu \mathrm{m}$ silica spheres in a glycerol-water-mixture. Scale bar $10 \mu \mathrm{m}$. (D) Schematic of optical phase delay as plane wavefronts traverse sphere. (E) Schematic relating the shape of a sessile droplet wetting a surface to its projected height. (F) QPM linescan (black) along white dashed line in (C) and the surface fit function evaluated along the same line (red, Adj. $R^{2}=0.997$ ). (G) Index difference $(\Delta \mathrm{n})$ vs. R extracted from fits to individual silica spheres in glycerol-water-mixtures of 4 different refractive indicies (colors). Error bars are $95 \%$ confidence intervals. Probability histograms at right. $(H)$ Index difference measured with QPM vs that expected for silica spheres in difference glycerol-water mixtures (black) and for a dextran-rich droplet coexisting with a PEG-rich phase. For the silica spheres, dn theory accounts for an estimated bead porosity of $35 \%$. Error bars are standard deviation. Solid line is $y=x$.

\section{Fig 2: QPM measures protein concentration in condensates with high precision}

QPM (A) and ODT (B) images of untagged PGL condensates under similar conditions $(\mathrm{pH} 7.4$ (both); $23.0{ }^{\circ} \mathrm{C}$ (QPM) and $21.8^{\circ} \mathrm{C}$ (ODT); $87 \mathrm{mM} \mathrm{KCl}$ (QPM) and $75 \mathrm{mM} \mathrm{KCl}$ (ODT). Scale bar $10 \mu \mathrm{m}$. (C) Comparison of concentrations measured in individual PGL3 condensates by QPM $(\mathrm{N}=269)$ and ODT $(\mathrm{N}=355)$. The coefficient of variation (stdev/mean) across the sampled population is 3-fold lower for QPM. (D) Confocal fluorescence image of SNAP-TAF15(RBD) condensates ( $8 \%$ labeled with Alexa Fluor 546) in $100 \mathrm{mM} \mathrm{KCl}$, Tris pH 7.4, $26^{\circ} \mathrm{C}$. Scale bar $5 \mu \mathrm{m}$. (E) Fluorescence intensity along line indicated in (D). Highlighted regions indicate the characteristic intensity in the condensed (red) and dilute (blue) phases, giving an intensity ratio of 65. (F) Comparison of SNAP-TAF15(RBD) concentrations in condensates measured by three methods: fluorescence intensity ratio (confocal), volume measurements in emulsion drops and mass conservation (volume), and QPM. Errorbars are standard deviation.

Fig 3: QPM is compatible with temperature-dependent binodal measurements

(A) Index difference measured by QPM for GFP-TAF15(RBD) condensates in $150 \mathrm{mM} \mathrm{KCl}$ at different temperatures. (B) Refractive index of buffer with $150 \mathrm{mM} \mathrm{KCl}$ at same temperatures. (C) Temperature-adjusted refractive index increment (dn/dc) (Zhao et al 2011 BiophysJ). (D) Condensed branch of binodal (Temp vs concentration) for GFP-TAF15(RBD) following adjustments for temperature-dependent coefficients.

\section{Fig 4: QPM reveals that PGL3 condensate density increases with time}

(A) Timelapse of untagged PGL3 condensate (top, amplitude; bottom, QPM). Scale bar $10 \mu \mathrm{m}$. Concentration (B), volume (C) and number of protein molecules in the condensate (D) for the example in (A). Time is relative to induction of phase separation. (E) Time-dependence of concentration is identical for $\mathrm{N}=25$ differently sized condensates. (F) Normalized volume varies continuously with initial condensate size $\left(R_{0}\right)$. Initial shrinkage rate decreases with increasing $R_{0}$. (G) Fraction of molecules in 25 individual condensates over time. 
bioRxiv preprint doi: https://doi.org/10.1101/2020.10.25.352823; this version posted October 25, 2020. The copyright holder for this preprint (which was not certified by peer review) is the author/funder, who has granted bioRxiv a license to display the preprint in perpetuity. It is made available under aCC-BY-ND 4.0 International license.

QPM Method

McCall et al.

Table 1. Compositions of biomolecular condensates in vitro.

\begin{tabular}{|l|c|c|c|c|c|}
\hline \multicolumn{1}{|c|}{ Construct } & $\begin{array}{c}\text { Conditions } \\
\left(\mathrm{T} \mathrm{in}^{\circ} \mathrm{C},[\mathrm{salt}], \mathrm{pH}\right)\end{array}$ & $\begin{array}{c}{[\text { Protein }]_{\text {cond }}} \\
\mathrm{mg} / \mathrm{ml}\end{array}$ & $\begin{array}{c}\text { Protein Volume } \\
\text { Fraction }^{\text {a }}\end{array}$ & $\begin{array}{c}\text { Partition } \\
\text { Coefficient }\end{array}$ & Method \\
\hline PGL3 & $(25.0,75 \mathrm{mM}, 7.4)$ & $87.0 \pm 1.7$ & 0.064 & n.d. & QPM \\
\hline PGL3 & $(21.5,87 \mathrm{mM}, 7.4)$ & $99.2 \pm 5.9$ & 0.073 & n.d. & ODT \\
\hline PGL3-mEGFP & $(21.5,87 \mathrm{mM}, 7.4)$ & $113.2 \pm 8.6$ & 0.084 & n.d. & ODT \\
\hline SNAP-TAF15(RBD) & $(37.0,50 \mathrm{mM}, 7.4)$ & $393.7 \pm 7.2$ & 0.29 & $3200^{\mathrm{b}}$ & QPM \\
\hline GFP-FUS & $(21.0,150 \mathrm{mM}, 7.4)$ & $337.3 \pm 8.2$ & 0.25 & $860^{c}$ & QPM \\
\hline
\end{tabular}

${ }^{\mathrm{a}} \bar{v} \approx 0.74 \mathrm{~mL} / \mathrm{g}$ for PGL3 constructs, $\bar{v} \approx 0.71 \mathrm{~mL} / \mathrm{g}$ for TAF15 and FUS constructs

${ }^{\mathrm{b}} \mathrm{c}_{\text {dil }}=1.97 \pm 0.09 \mu \mathrm{M}, \mathrm{M}_{\mathrm{w}}=62.92 \mathrm{kDa}$; (29)

${ }^{c} C_{\text {dil }}=4.87 \pm 0.48 \mu \mathrm{M}, \mathrm{M}_{\mathrm{w}}=80.38 \mathrm{kDa}$; (29) 
A

QPM untagged PGL3

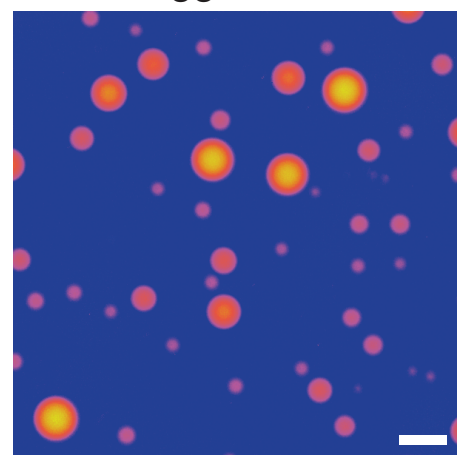

D Confocal fluorescence SNAP-TAF15(RBD)

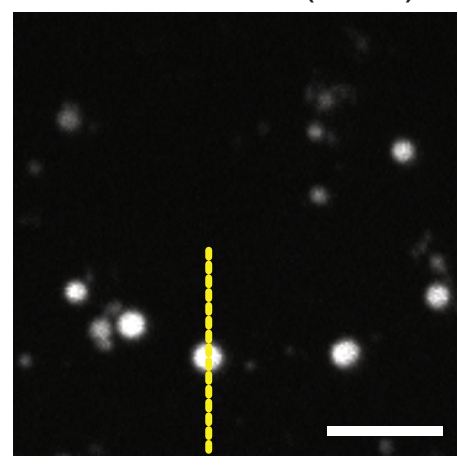

B $\varphi(\mathrm{rad})$

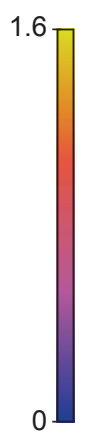

ODT

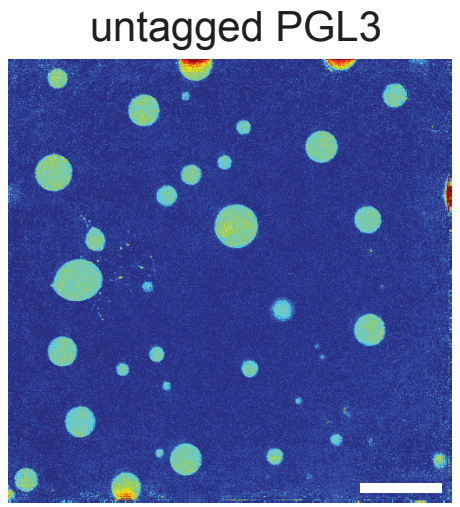

E

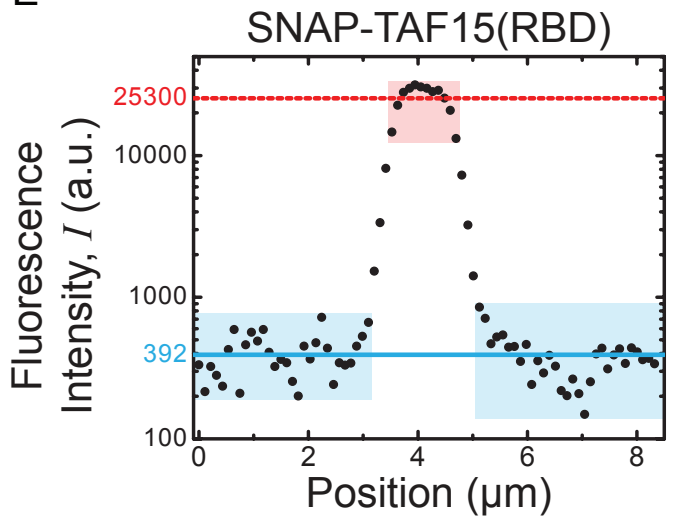

C

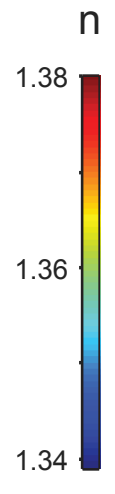

F
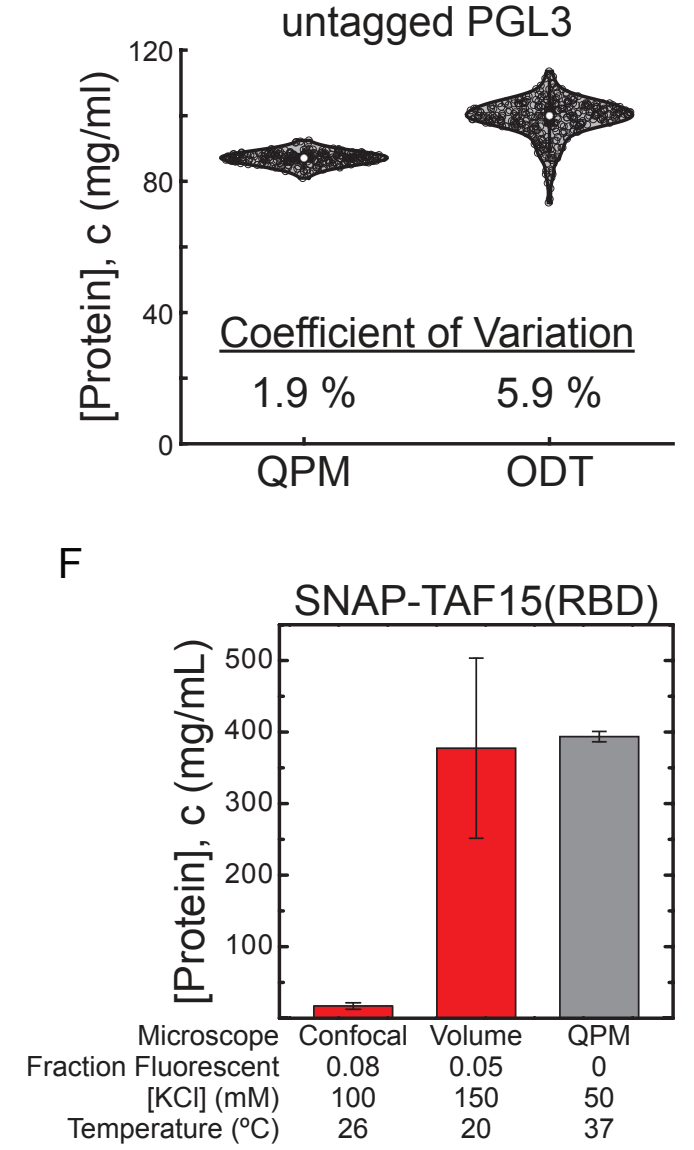

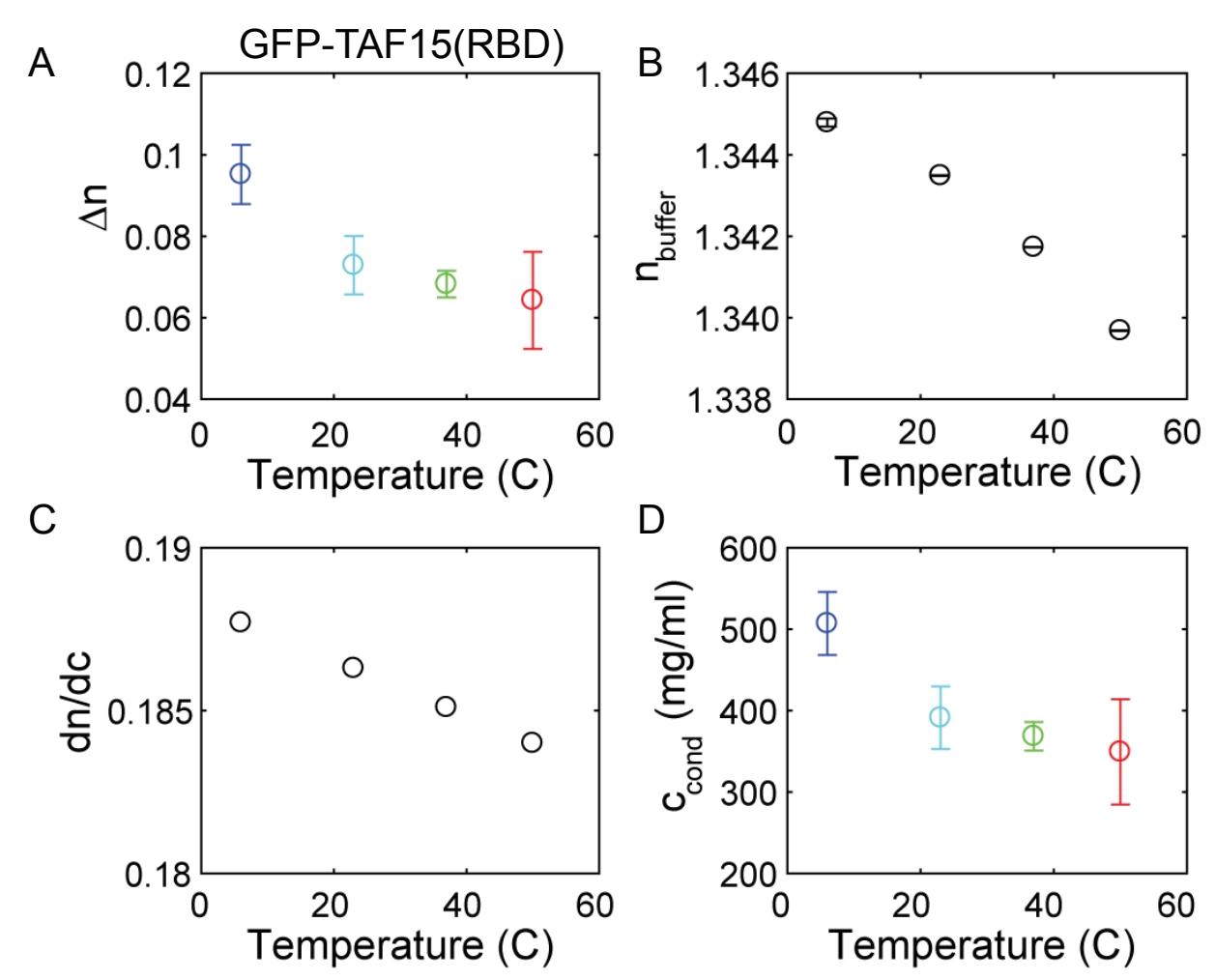
A untagged PGL3

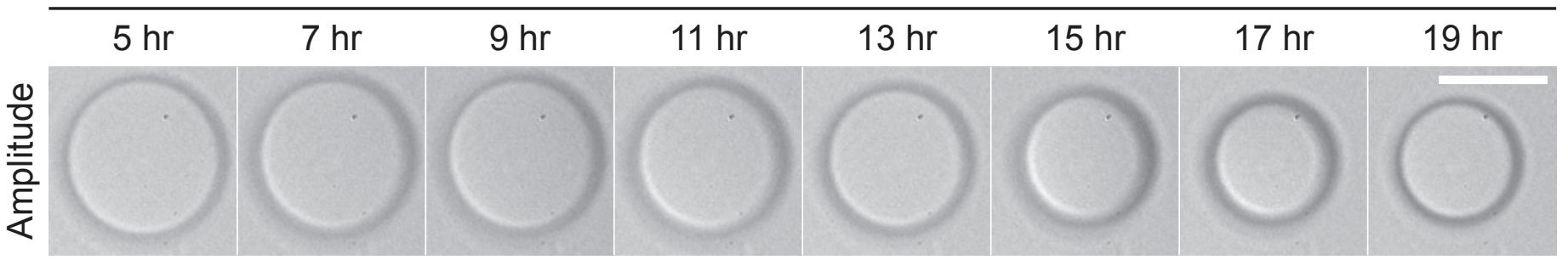

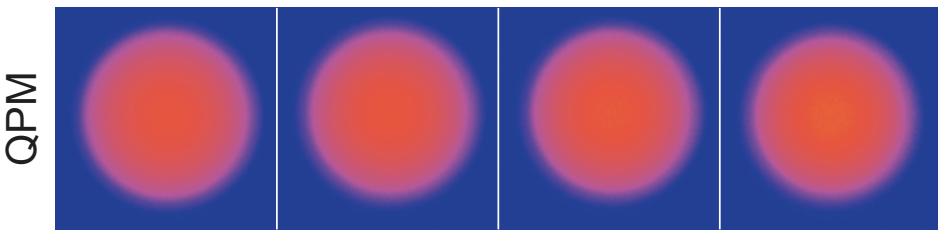

B

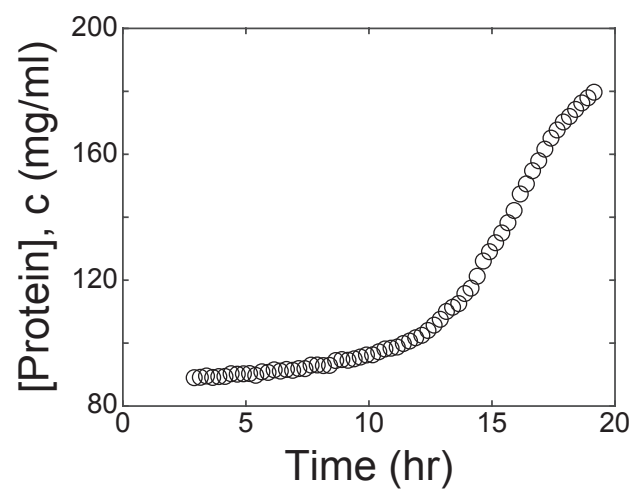

E

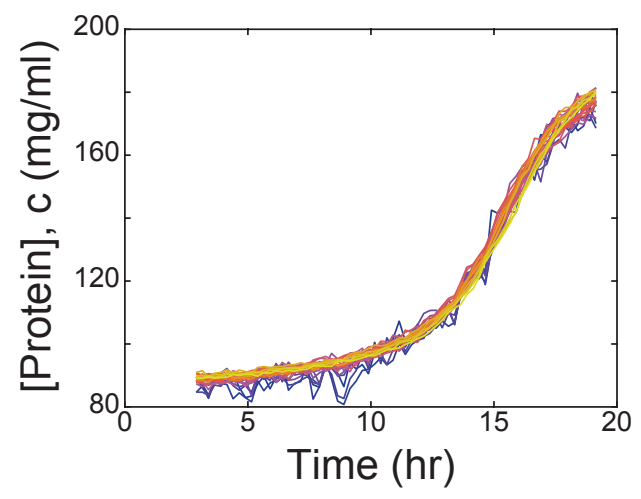

C

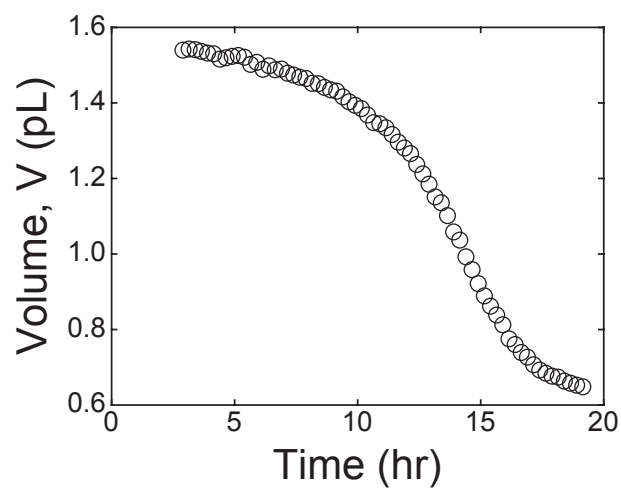

F

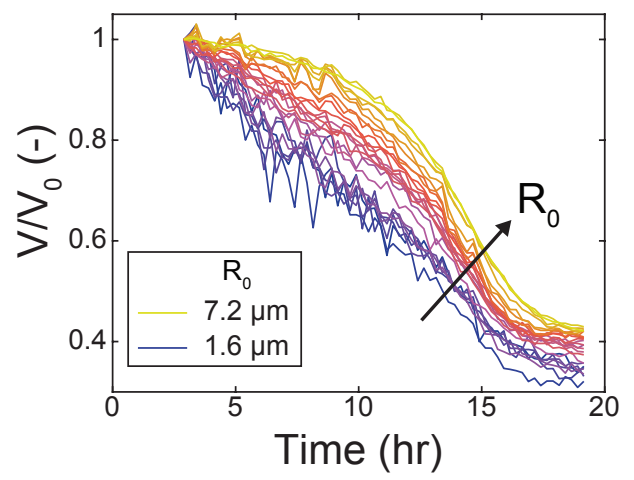

D

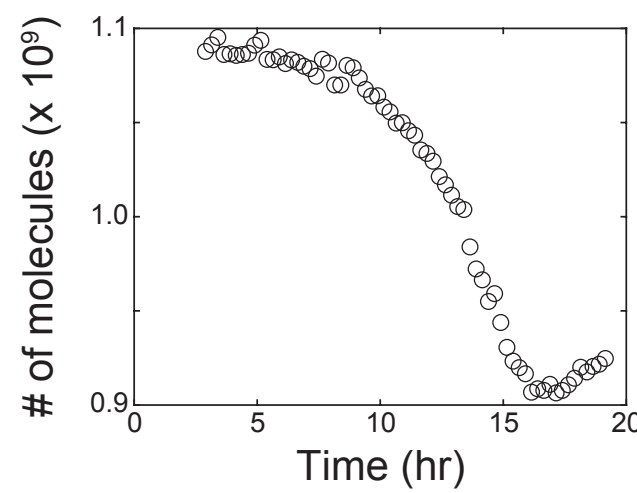

G

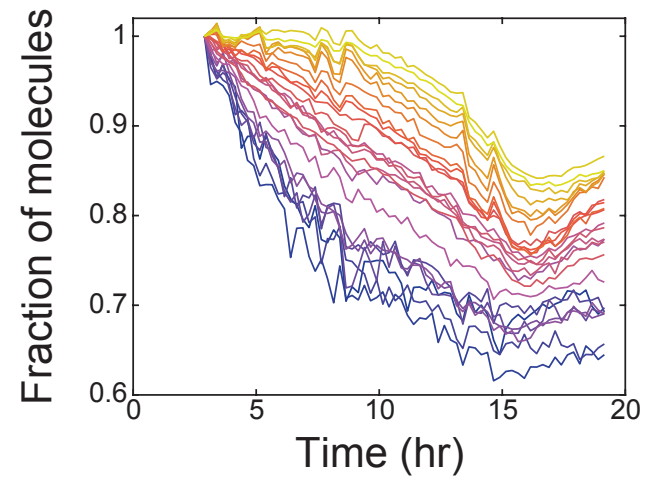

